\title{
A Collaborative Framework to Improve Public Participation Practice
}

\author{
Aulia Akbar ${ }^{\dagger}$ \\ Faculty of Geo-Information Science and Earth Observation \\ (ITC), The University of Twente, Enschede, The \\ Netherlands \\ a.akbar@utwente.nl \\ Javier A Martinez \\ Faculty of Geo-Information Science and Earth Observation \\ (ITC), The University of Twente, Enschede, The \\ Netherlands \\ j.a.martinez@utwente.nl
}

\begin{abstract}
In Indonesia, an annual participatory planning practice called Musrenbang is implemented to produce village development plans through public meetings. Being an obligatory process, Musrenbang is often poorly implemented due to problems such as power relations and disagreement among stakeholders. Enabling the stakeholders to find common understanding through knowledge integration is crucial to minimize these issues. As most villages do not have proper maps, we developed a collaborative spatial learning methodology to enable the village stakeholders to participate in the mapping process. Through the mapping exercise it is expected that we can support production of the village maps, and contribute to integrate stakeholders' spatial knowledge; helping them to minimize the power gaps and to find common understanding through social learning experiences. Ultimately, it is expected that the developed methodology will improve the Musrenbang implementation at village level.
\end{abstract}

\section{KEYWORDS}

Musrenbang, participatory mapping, participatory planning, public participation

\section{ACM Reference Format:}

Aulia Akbar ${ }^{\dagger}$, Johannes Flacke, Javier A Martinez, and Martin van Maarseveen. 2020. A Collaborative Framework to Improve Public Participation Practice. In Proceedings of the 16th Participatory Design Conference 2020Participation(s) Otherwise - Vol. 2 (PDC '20: Vol. 2), June 15-20, 2020, Manizales, Colombia. ACM, New York, NY, USA, 5 pages. https://doi.org/10.1145/ 3384772.3385126

Permission to make digital or hard copies of all or part of this work for personal or classroom use is granted without fee provided that copies are not made or distributed for profit or commercial advantage and that copies bear this notice and the full citation on the first page. Copyrights for components of this work owned by others than the author(s) must be honored. Abstracting with credit is permitted. To copy otherwise, or republish, to post on servers or to redistribute to lists, requires prior specific permission and/or a fee. Request permissions from permissions@acm.org.

PDC '20: Vol. 2, June 15-20, 2020, Manizales, Colombia

(c) 2020 Copyright held by the owner/author(s). Publication rights licensed to ACM ACM ISBN 978-1-4503-7606-8/20/06 ..\$15.00

https://doi.org/10.1145/3384772.3385126

\author{
Johannes Flacke \\ Faculty of Geo-Information Science and Earth Observation \\ (ITC), The University of Twente, Enschede, The \\ Netherlands \\ j.flacke@utwente.nl \\ Martin van Maarseveen \\ Faculty of Geo-Information Science and Earth Observation \\ (ITC), The University of Twente, Enschede, The \\ Netherlands \\ m.f.a.m.vanmaarseveen@utwente.nl
}

\section{INTRODUCTION}

Governance processes including the public participation cannot be separated from geographical space and place. Consequently, spatial knowledge, the knowledge of how individuals, social groups, and institutions perceive particular places into their characteristics and meanings [1], becomes significant in supporting the participatory processes. The participatory process enables various types of spatial knowledge to be produced, used and exchanged among stakeholders [2]. Integrating knowledge of diverse sectors by using spatial data and information can support mutual learning processes leading to knowledge co-production [3]. An approach that provides spatial data and information support is necessary to allow dynamic deliberative process while eliciting and integrating both tacit and explicit knowledge [4]. Utilizing the spatial knowledge through the learning approach is useful to promote the elicitation of tacit and explicit knowledge in a participatory process.

With respect to above arguments, we argue that the stakeholders' spatial knowledge in the participatory process is useful to enhance the implementation of public participation practice. Thus, a social learning approach that promotes the elicitation of tacit and explicit spatial knowledge through co-production of knowledge is crucial achieve better implementation of public participation. We use the public meeting practice in Indonesia, so-called Musrenbang as the case of this study. Through Musrenbang implementation in five villages in Deli Serdang district of Indonesia, this study aims to explore the role of our collaborative spatial learning methodology (CSLM) to make use the spatial knowledge owned by village stakeholders to enhance the current Musrenbang practice. We propose a conceptual framework of how to make use the spatial knowledge to enable the social learning while promoting the knowledge coproduction among the stakeholders. The developed framework will also consider the process of elicitation and integration of tacit and explicit knowledge to achieve better social learning experiences for the stakeholders. 


\section{ENHANCING PUBLIC PARTICIPATION PROCESSES}

Public participation has been practiced in many countries as a prerequisite for successful decentralization, democracy and good governance and has evolved theoretically and practically $[5,6]$.

Participatory process involves different stakeholders from many backgrounds in nature. Consequently, various types of knowledge involved are exercised during the process. When utilizing different types of knowledge that the stakeholders have, it is important to note that each stakeholder involved in the participatory processes has their own perspective and views towards any issues discussed. Their perspectives and views basically have to be constructed and translated into meaningful knowledge to ensure the effectiveness of the deliberative processes while improve the stakeholders' collaboration. Managing various types of knowledge owned by a range of stakeholders involved is then becoming an essential part in the participatory planning and budgeting processes.

\section{SOCIAL LEARNING AND KNOWLEDGE CO-PRODUCTION}

The transdisciplinary approach enables the science and society to engage actively in the knowledge production process, even though the participants may come from non-academia environment [7]. Nonaka \& Takeuchi [8] suggest the knowledge production as a circling process that involves two types of knowledge: explicit and tacit knowledge. Explicit knowledge is a systematic and identifiable knowledge which can be expressed or transferred in words or numbers, while tacit knowledge is a personal knowledge rooted in individuals which is not easily transferred or communicated [9].

Linking the tacit and explicit knowledge helps to make the tacit knowledge becoming understandable for stakeholders and enhancing its relevance for the planning and decision-making purposes [10]. To describe the shift from tacit knowledge into explicit knowledge, Nonaka \& Takeuchi [8] propose the SECI model through four key phases: socialization (tacit with tacit), externalization (tacit with explicit), combination (explicit with explicit), and internalization (explicit with tacit). The model is useful to illustrate the knowledge co-production and integration as a learning and social process [3].

Social learning can be described as a learning process that takes place through participatory systems such as groups or communities in an unexpected and uncertain condition, to formulate solutions and actions to solve problems by utilizing their own resources and capacity [11]. It requires a diverse group of stakeholders to develop a common understanding and exchange knowledge among individuals in the group [12]-[14]. To achieve the learning experiences, participatory activities can act as a trigger for social learning. The participatory process bring diverse stakeholders into a learning process which enables them to better interact, communicate, and exchange their knowledge [12,14]. According to Romina [15], the social learning promotes the knowledge production through four fundamental dimensions: cognitive, moral, relational, and trust dimension. The knowledge is acquired through the interaction of various stakeholders in the participatory setting.
Based on the reflection above, the focus of our research is to verify if by developing a suitable framework that enables the knowledge co-production and social learning among the stakeholders, particularly through utilizing the stakeholders' spatial knowledge, a better public participation practice can be achieved.

\section{RESEARCH DESIGN AND METHODS}

\subsection{The case study: the Musrenbang practice}

This study focuses on the annual Musrenbang at the village level as the first phase of the hierarchical planning stages in Indonesia, which provides more opportunities for citizens to participate in the processes.

At the village level, the annual Musrenbang is implemented through a public meeting that involves various stakeholders, from government officials, citizens, to other stakeholders ranging from the grass-roots organizations, non-governmental organizations (NGOs), community leaders, religious leaders, and private sectors. The main output of Musrenbang is the village budget and development plans. [16]. The stakeholder power gaps, lack of data/information to support the meeting are two main impediments to the effectiveness of the Musrenbang practice [16, 17].

\subsection{Study Area}

The study area is the Deli Serdang district in North Sumatra Province of Indonesia. We selected five villages according to the following criteria: (1) the village is located in different sub-districts; (2) the ethnicity of the population is primarily Javanese; (3) the primary livelihood of the population is farming and agriculture; (4) the village officials are willing to participate in this study. From five villages, we selected three villages for the participatory mapping workshop using the Collaborative Spatial Learning Methodology (CSLM). Based on the criteria, the Denai Lama, Kolam, and Kramat Gajah, Sidoarjo I Pasar Miring, Tandem Hulu II villages were chosen as the locations of the case study. The first three villages will experience the participatory mapping exercises. Sidoarjo I Pasar Miring will use third parties to map their village, while Tandem Hulu II will not experience any mapping activities at all.

\subsection{Methods}

Data collection included participatory mapping workshop, direct observation, focus group discussion, and semi-structured in-depth interviews. The data were collected from end of October 2019 to February 2020. We developed a conceptual framework and applying it through the participatory mapping workshops with the stakeholders to examine the social learning and knowledge co-production process during the workshops. We also visited the Musrenbang in the villages on January-February 2020 to see the impacts of the collaborative spatial learning towards the Musrenbang implementation. The same data collection methods (without the participatory mapping workshop) were used to evaluate the impacts of the learning methodology to the current Musrenbang practice. 


\section{COLLABORATIVE SPATIAL LEARNING METHODOLOGY (CSLM) FRAMEWORK}

\subsection{Design rationale}

Three mapping workshops have been implemented during the fieldwork. The workshop aim was to test the CSLM in (1) stimulating the tacit knowledge to become explicit, (2) integrating different types of spatial knowledge, (3) producing the village maps, and (4) facilitating knowledge co-production and social learning.

The participatory mapping workshop were implemented in three villages in Deli Serdang district (Denai Lama, Kolam, Kramat Gajah). The mapping exercise will be implemented on October-November 2019. Each village will spend around 2 weeks for the implementation. The researcher acted as the facilitator of the workshops.

The produced village maps then will be used to support the Musrenbang participatory planning practice by displaying and using the village maps during the Musrenbang deliberative processes.

\subsection{The framework}

The conceptual framework provides the rationale of the CSLM and guides the researchers in designing the workshops. The SECI model [8] is employed with the specific focus to stimulate the stakeholders' tacit knowledge to become explicit during the implementation of CSLM which promote the knowledge co-production [12] and social learning $[14,15]$ processes to occur.

The conceptual framework can be seen below.

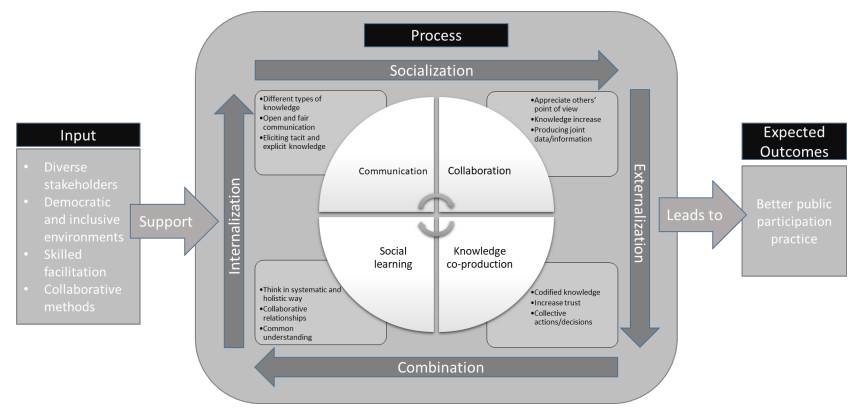

Figure 1: Conceptual framework of Collaborative Spatial Learning Methodology Adapted from various sources $[8,12$, 14, 15]

The framework consists of several steps which include the knowledge conversion (tacit and explicit knowledge) in the SECI model, objectives/goals for each step, and the expected outputs from each objectives/goals.

The following sections elaborate on each of the steps of the framework.

5.2.1 Input (see Figure 1, left side). The CSLM considers some inputs that can be used to apply the concept into practice: diverse stakeholders, democratic and inclusive environment, skilled facilitation, and collaborative methods. Diverse stakeholders have different knowledge and values and it is essential to acknowledge their existence and influence/interest that their contributions determine the success or failure of a participatory process [18].
The involvement of many stakeholders requires a democratic and inclusive environment, which enables participants to contribute positively and ensures that their contributions are taken into consideration[14]. A skilled facilitation is also needed to guide participants following the schedule and to give them the same opportunity to contribute [14].

The CSLM also requires to use the right collaborative methods. As the main aim of the CSLM is to encourage stakeholders to express their knowledge in the deliberative process, we employ the participatory mapping exercise for the workshops [19]-[22].

Different treatments were given to the chosen villages as can be seen in Table 1 below.

\subsubsection{Process (see Figure 1, central part).}

Communication. The communication component is successfully instituted if the participants are aware that they can contribute to the participatory process using their tacit knowledge [23]; the communication is fair and open to all participants [24]; and participants are able to express their tacit and explicit knowledge [25]. To achieve this, we asked the participants to do a sketch mapping of their village to stimulate the elicitation of tacit and explicit knowledge. The sketch mapping is helpful to stimulate participants' spatial knowledge and understanding since it provides free choices to draw and visualize their desired spatial objects [26]. Further, this exercise will also be helpful to start the conversation among them when comparing the drawing results.

Collaboration. Collaboration is another key factor to enable social learning experiences among multi stakeholders [27]. To achieve a collaborative dialogue, participants should be able to appreciate others' perspective. Participants should acknowledge the difference of each one knowledge [28], and that these differences may increase knowledge [29,30]. Eventually, this experience is useful to initiate the joint data/information production through participatory village mapping exercise. Participants learn how to integrate different types of spatial knowledge they have to create village maps.

In this phase, the mapping tools and methods are introduced to the participants. A satellite image (analogue (1) and digital (2)) of the village areas is presented to the participants. They were asked to look at the satellite image, to orient and to identify some points of interests in their village. They are free to discuss and interact with their colleague when exploring the spatial information, and to learn new things from others. They also start to understand other opinions and interests, and also to collaborate for achieving common goals.

Knowledge co-production. Participants were asked to produce several village maps in a participatory manner. The maps produced consist of delineation map, land use/land cover map, and infrastructure map. There was an introduction of how to do the participatory mapping exercise and what are the tools/markers/symbols used during the mapping exercise. The satellite image served as the base image for doing the mapping exercise. To produce the maps, participants were asked to work collaboratively to decide the most prioritized programs through deliberative process to build consensus [18]. Participants also became to know each other interests and competencies, so-called "know-who" [23], as the group members start to understand who is affected or impacted by the decisions 
Table 1: Different treatments given to the villages

\begin{tabular}{|l|l|l|l|l|}
\hline Villages & Denai Lama and Kramat Gajah & Kolam & Sidoharjo I Pasar Miring & Tandem Hulu II \\
\hline Treatment & $\begin{array}{l}\text { Digital Participatory Village } \\
\text { Mapping }\end{array}$ & $\begin{array}{l}\text { Analogue Participatory } \\
\text { Village Mapping }\end{array}$ & $\begin{array}{l}\text { Maps are made by third } \\
\text { party }\end{array}$ & $\begin{array}{l}\text { No mapping } \\
\text { activities }\end{array}$ \\
\hline
\end{tabular}

they make, and people among the group who are able to solve and act on behalf of the group. By knowing this, they would be able to distribute the tasks and formulate common strategies to deal with identified problems. Intense communication and collaboration among participants would reach the peak at this phase. Based on the communication, collaboration, and social learning experiences gained in the previous sessions, the knowledge co-production process will occur from the proposed development mapping exercise.

Social learning. The communication and collaboration in the previous stages will contribute to the social learning process. It occurs whenever multi stakeholders with different interest, influences, and perspectives acknowledge the differences, sit together in a dialogue, deal with their differences and conflicts to achieve common purpose [24]. Thus, at this stage, the participants are expected to gain learning experiences individually and within a group. Through the learning environment, participants begin to think systematically and holistically [14, 31, 32], create collaborative relationships $[28,33]$, and develop common understanding within the group $[29,33]$.

Expected Outcomes (see Figure 1, right side). The final decision about the marks on the satellite images made by the participants were then brought by the workshop facilitators to be drawn using the GIS software. The village maps produced represent the tacit knowledge has become explicit and ultimately become codified knowledge in the map standard format. The post-processing maps were verified by the workshop participants before finalization. The final maps were then given in the digital and analogue formats to the village to be used in the Musrenbang public participation practice. An evaluation framework to assess the impact of using maps on the Musrenbang implementation were made to evaluate how the geospatial data like maps can improve the current Musrenbang practice.

\section{CONCLUSION}

The CSLM is developed to help the social learning and knowledge co-production of the village stakeholders. From the mapping workshop it is expected that the communication, collaboration, social learning, and knowledge co-production experiences would bring the participants to learn and change. The learning experiences would enhance the knowledge enhancement and mutual understanding among the involved stakeholders $[15,35]$. It is expected that the learning experience would be useful to enhance the Musrenbang practice as the participants able to better participate in the Musrenbang public participation practice. Currently, we have finished our data collection, and we are now at the stage of starting the analysis of the data collected from the field.

\section{ACKNOWLEDGMENTS}

We would like to thank the Ministry of Finance for the Republic of Indonesia's Indonesian Endowment Fund for Education (LPDP) for supporting this $\mathrm{PhD}$ research.

\section{REFERENCES}

[1] S. Elwood, "Beyond cooptation or resistance: Urban spatial politics, community organizations, and GIS-based spatial narratives," Ann. Assoc. Am. Geogr., vol. 96, no. 2, pp. 323-341, 2006.

[2] K. Pfeffer, I. Baud, E. Denis, D. Scott, and J. Sydenstricker-Neto, "Participatory spatial knowledge management tools: empowerment and upscaling or exclusion?" Information, Commun. Soc., vol. 16, no. 2, pp. 258-285, 2013.

[3] R. Shrestha, H. Köckler, J. Flacke, J. Martinez, and M. van Maarseveen, "Interactive Knowledge Co-Production and Integration for Healthy Urban Development," Sustainability, vol. 9, no. 11, 2017.

[4] R. Shrestha, J. Flacke, J. Martinez, and M. van Maarseveen, "Knowledge CoProduction and Social Learning on Environmental Health Issues," in GIS in Sustainable Urban Planning and Management: A Global Perspective, CRC Press, 2018, pp. 83-102.

[5] R. Tandon, "Participation, citizenship and democracy: Reflections on 25 years' of PRIA," Community Dev. F., vol. 43, no. 3, pp. 284-296, 2008.

[6] A. Fung, "Putting the Public Back into Governance: Th e Challenges of Citizen Participation and Its Future," Public Adm. Rev., vol. 75, no. 4, pp. 513-522, 2015.

[7] R. Scholz, H. Mieg, and J. Oswald, "Transdisciplinarity in groundwater management - towards mutual learning of science and society," Water. Air. Soil Pollut., vol. 123 , pp. $477-487,2000$.

[8] I. Nonaka and H. Takeuchi, The knowledge-creating company: how fapanese companies create the dynamics of innovation. Oxford University Press, 1995.

[9] I. Nonaka and N. Konno, "The Concept of 'Ba': Building a Foundation for Knowledge Creation," Calif. Manage. Rev., vol. 40, no. 3, pp. 40-54, 1998.

[10] M. te Brömmelstroet and P. Schrijnen, "From planning support systems to mediated planning support: a structured dialogue to overcome the implementation gap," Environ. Plan. B Plan. Des., vol. 37, no. 1, pp. 3-20, 2010.

[11] D. Wildemeersch, T. Jansen, J. Vandenabeele, and M. Jans, "Social Learning: a new perspective on learning in participatory systems," Stud. Contin. Educ., vol. 20, no. 2, pp. 251-265, Nov. 1998.

[12] D. Armitage, F. Berkes, A. Dale, E. Kocho-Schellenberg, and E. Patton, "Comanagement and the co-production of knowledge: Learning to adapt in Canada's Arctic," Glob. Environ. Chang., vol. 21, no. 3, pp. 995-1004, Aug. 2011.

[13] D. Armitage, M. Marschke, and R. Plummer, "Adaptive co-management and the paradox of learning," Glob. Environ. Chang., vol. 18, no. 1, pp. 86-98, 2008.

[14] G. Dana and K. Nelson, "Social Learning Through Environmental Risk Analysis of Biodiversity and GM Maize in South Africa," Environ. Policy Gov., vol. 22, no. 4, pp. 238-252, Jul. 2012.

[15] R. Romina, "Social learning, natural resource management, and participatory activities: A reflection on construct development and testing," NFAS - Wageningen 7. Life Sci., vol. 69, pp. 15-22, 2014

[16] A. Sopanah, "Ceremonial Budgeting: Public Participation in Development Planning at an Indonesian Local Government Authority," 7. Appl. Manag. Account. Res., vol. 10, no. 2, pp. 73-84, 2012.

[17] A. Akbar, J. Flacke, J. Martinez, and M. F. A. . van Maarseveen, "Participatory Planning Practice in Rural Indonesia: A Sustainable Development Goals-based Evaluation," Submitt. to Community Dev. f. f. Community Dev. Soc.

[18] J. Innes and D. Booher, "Consensus building and complex adaptive systems: A framework for evaluating collaborative planning," f. Am. Plan. Assoc., vol. 65, no. 4, pp. 412-423, 1999.

[19] K. Bauer, "On the politics and the possibilities of participatory mapping and GIS: using spatial technologies to study common property and land use change among pastoralists in," Cult. Geogr., vol. 16, pp. 229-252, 2009.

[20] S. Kienberger, "Participatory mapping of flood hazard risk in Munamicua, District of Búzi, Mozambique," f. Maps, vol. 10, no. 2, pp. 269-275, 2014.

[21] G. Brown and M. Kyttä, "Key issues and research priorities for public participation GIS (PPGIS): A synthesis based on empirical research," Appl. Geogr., vol. 46, pp. 122-136, 2014.

[22] G. Brown, D. Weber, and K. de Bie, "Is PPGIS good enough? An empirical evaluation of the quality of PPGIS crowd-sourced spatial data for conservation planning," Land use policy, vol. 43, pp. 228-238, 2015.

[23] B. Johnson, E. Lorenz, and B. Lundvall, "Why all this fuss about codified and tacit knowledge?," Ind. Corp. Chang., vol. 11, no. 2, pp. 245-262, 2002. 
[24] E. Mostert, C. Pahl-Wostl, Y. Rees, B. Searle, D. Tàbara, and J. Tippett, "Social Learning in European River-Basin Management: Barriers and Fostering Mechanisms from 10 River Basins," Ecol. Soc., vol. 12, no. 1, 2007.

[25] J. Friedmann, "Planning as Social Learning," URD Work. Pap. Ser., pp. 1-8, 1981.

[26] G. Rambaldi, P. Kyem, M. McCall, and D. Weiner, "Participatory spatial information management and communication in developing countries," Electron. f. Inf. Syst. Dev. Ctries., vol. 25, no. 1, pp. 1-9, 2006.

[27] C. Pahl-Wostl, M. Craps, A. Dewulf, E. Mostert, D. Tabara, and T. Taillieu, "Social Learning and Water Resources Management," Ecol. Soc., vol. 12, no. 2, 2007.

[28] T. Webler, H. Kastenholz, and O. Renn, "Public participation in impact assessment: a social learning perspective," Environ. Impact Assess. Rev., 1995.

[29] E. Garmendia and S. Stagl, "Public participation for sustainability and social learning: Concepts and lessons from three case studies in Europe," Ecol. Econ., vol. 69 , no. 8, pp. $1712-1722,2010$.
[30] A. J. Sinclair and A. P. Diduck, "Public involvement in EA in Canada: a transformative learning perspective," vol. 21, pp. 113-136, 2001.

[31] K. A. Johnson et al., "Using Participatory Scenarios to Stimulate Social Learning for Collaborative Sustainable Development” Ecol Soc., vol. 17, no. 2, p. art9, 2012.

[32] R. Shrestha, J. Flacke, J. Martinez, and M. van Maarseveen, "Interactive cumulative burden assessment: Engaging stakeholders in an adaptive, participatory and transdisciplinary approach," Int. F. Environ. Res. Public Health, vol. 15, no. 2, 2018.

[33] T. Schusler, D. Decker, and M. Pfeffer, "Social Learning for Collaborative Natural Resource Management," Soc. Nat. Resour., vol. 16, no. 4, pp. 309-326, Apr. 2003.

[34] K. Pfeffer, J. Martinez, I. Baud, and N. Sridharan, "Knowledge production in local governance systems through qualitative Geographical Information System (GIS)," in Environment and Urbanization Asia, 2010.

[35] R. Romina, "The social learning discourse: Trends, themes and interdisciplinary influences in current research," Environ. Sci. Policy, vol. 25, pp. 157-166, 2013. 